\title{
Exploring the need to update lung age equations
}

\author{
*Wendy Newburya, Jonathan Newbury ${ }^{b}$, Nancy Briggs ${ }^{c}$, Alan Crockett ${ }^{d}$ \\ a Discipline of General Practice, School of Population Health and Clinical Practice, University of Adelaide; Spencer Gulf Rural Health School, \\ University of Adelaide and University of South Australia \\ ${ }^{b}$ Professor, Spencer Gulf Rural Health School, University of Adelaide and University of South Australia \\ ' Data Management \& Analysis Centre, Discipline of Public Health, University of Adelaide \\ ${ }^{d}$ Associate Professor, Primary Care Respiratory Research Unit, Discipline of General Practice, School of Population Health and Clinical Practice, \\ University of Adelaide
}

Received 22nd November 2009; resubmitted 26th January 2010; revised 12th March 2010; accepted 23rd March 2010; online 12th May 2010

\begin{abstract}
Aims: A renewed interest in lung age is evidenced by recent smoking cessation publications. This research compares the original Morris lung age equations (1985) with contemporary Australian lung age equations.

Methods: Both lung age equations were applied to the spirometry results of two sub-groups (never-smokers n=340, and current smokers $\mathrm{n}=50$ ) from an independent dataset. Means of both lung age estimates were compared to the mean of the chronological age of each group by paired Student's t-test.

Results: The Morris lung age estimates were paradoxically lower (younger) than chronological age in both groups. The new Australian equation produced lung age estimates that were equivalent to chronological age in the never-smoker group and significantly higher (older) than chronological age in the current smoker group.

Conclusions: These results strongly suggest that the Morris lung age equations are in need of review. The use of contemporary lung age equations may translate into greater success for smoking cessation programs. The new Australian equations seem to possess internal validity.

C 2010 Primary Care Respiratory Society UK. All rights reserved.

W Newbury et al. Prim Care Resp J 2010; 19(3): 242-247

doi:10.4104/pcrj.2010.00029
\end{abstract}

Keywords Lung age, smoking cessation, spirometry

See linked editorial by Quanjer and Enright on page

197, and letter from Hansen on page 286

\section{Introduction}

Smoking has been shown to be detrimental to health for many years. ${ }^{1-7}$ Smoking has an adverse effect on forced expiratory volume in one second $\left(\mathrm{FEV}_{1}\right)$ throughout a lifetime, reducing the maximal $F E V_{1}$ achieved, bringing forward the age of onset of decline in $\mathrm{FEV}_{1}$, and hastening the rate of decline. ${ }^{8}$ The single most useful intervention to improve lung function in smokers with or without chronic obstructive pulmonary disease (COPD) is smoking cessation. One way to increase the quit rate in smokers could be to communicate lung function results in a manner that is easily understood and stimulates the desire to quit.
Lung age is an estimate that uses the observed $\mathrm{FEV}_{1}$ of a smoker to calculate the approximate age of a healthy nonsmoker with the same $\mathrm{FEV}_{1}$ based on predicted values, and can be a "potent motivator" in smoking cessation counselling. ${ }^{9}$ Equations for estimating lung age were first developed by Morris and Temple in $1985^{10}$ using earlier American predictive equations for spirometry published in 1971. ${ }^{11}$ The most relevant of the forced expiratory measures to determine lung age values was deemed to be $\mathrm{FEV}_{1} .^{10}$

Lung age equations were developed as an aid for smoking cessation counselling ${ }^{10}$ and the concept has been explored in several recent publications. One qualitative study explored acceptance of a graphical means to communicate lung function decline caused by smoking using a bar graph that compared

\footnotetext{
* Corresponding author: Mrs Wendy Newbury, Spencer Gulf Rural Health School, PO Box 3200, Port Lincoln SA 5606, South Australia. Tel: +61 419324529 Fax: +61 886832095 E-mail: wendy.newbury@adelaide.edu.au
} 
chronological age and estimated lung age, and found acceptance and better understanding of the concept of the greater rate of decline of $\mathrm{FEV}_{1}$ in smokers in this simple depiction. $^{12}$

Three publications describe randomised controlled trials (RCTs) of which one ${ }^{13}$ used a visual aid based on the Fletcher and Peto graph of age-related decline of lung function and the cumulative effect of smoking. ${ }^{3}$ In this study, Parkes et al. detected a significant improvement in the quit rate in their intervention group, using a graphical explanation of lung age compared to chronological age to give feedback of spirometry results. At 12 months follow-up the quit rate was 14\% in the intervention group (lung age group) and only $6 \%$ in the control group. ${ }^{13}$ The recent Cochrane Review, "Biomedical risk assessment as an aid for smoking cessation" 14 that conducted a meta-analysis of eleven RCTs, has identified Parkes' lung age study as the only intervention using spirometry which detected a significant effect.

The second RCT investigated perceived smoking-related health risks, worries, and desire to quit in college smokers with feedback on respiratory symptoms and a verbal explanation of lung age. ${ }^{15}$ Smoking cessation was not a primary outcome of this study. Perceptions of risk and worry, together with the desire to quit smoking, were not directly affected by lung age or respiratory symptoms feedback, possibly because of the young ages of the subjects. The third RCT used another adaptation of the same Fletcher and Peto graph, ${ }^{3}$ but only calculated lung age if $\mathrm{FEV}_{1}$ percent predicted was below $80 \%$, indicating possible impairment. ${ }^{16,17}$ This RCT failed to show differences in the quit rate between their intervention and control groups. ${ }^{16,17}$ In Japan, lung age has also been investigated in relation to smoking status and body mass index ${ }^{18}$ and in detecting pulmonary function abnormality in pulmonary diseases. ${ }^{19}$

Despite mixed results, this flurry of recent publications indicates a renewed interest in the use of lung age to educate smokers about the deterioration of their lung function caused by smoking. International guidelines for smoking cessation state that primary care encounters provide good opportunities for smoking cessation advice and that tailored advice may be more effective, ${ }^{20}$ and also that motivational counselling is of most use when it is relevant to the subject's risk status. ${ }^{21}$ The guidelines for spirometry by the American Thoracic Society (ATS) recommend that predictive equations should be derived from a 'relevant' population $^{22}$ and should be updated at least every 10 years. ${ }^{23}$ These recommendations should equally apply to equations that estimate lung age. However, the lung age equations in use today are those that were published in 1985.

This paper describes the comparison of new lung age equations derived from contemporary Australian data ${ }^{24}$ with the Morris lung age equations. ${ }^{10}$ The null hypothesis is that there will be no difference between lung age mean values.

\section{Methods}

The research methodology has previously been described in the literature. ${ }^{24}$ Briefly, the inclusion criteria included Caucasian ethnicity, and ages between 25 and 74 years. Volunteers were recruited from the broad semi-rural community in South Australia (SA) by advertising in the local media and the snowball technique. Exclusion criteria were a current or previous history of asthma or other chronic lung disease, current acute respiratory infection, current smokers, and past smokers if they had smoked more than 10 cigarettes per day for more than five years. ${ }^{24}$ The resulting Australian predictive normal equations for spirometric parameters were mathematically manipulated using the methods described by Morris and Temple ${ }^{10}$ with the equations being solved for age.

The age distributions of the samples used to generate both sets of predictive equations were examined. Lung age estimates obtained from both the SA and the Morris equations were compared using an independent workplace dataset, the Metropolitan Fire Service (MFS) of SA collected in 2007-8 (unpublished data). As this dataset contained few females $(n=13)$, the analyses reported here are restricted to males only.

Lung age estimates of two subgroups of the MFS dataset (male never-smokers (NS), n=340 and male current smokers (CS), $n=50$ ) were calculated by applying both lung age equations to the observed FEV 1 values for these subjects. Smoking status was selfreported. Paired t-tests were performed to compare the mean of the chronological age of the NS with the mean of the lung age estimates produced by each lung age equation. Comparisons of chronological age and lung age were repeated for the CS subgroup. Statistical significance was set at $p=0.05$. SPSS (Version 17) was used for statistical analysis.

Ethics approval for both the Port Lincoln study (H-086-2006) and the MFS study (H-057-2007) was given by the University of Adelaide Human Research Ethics Committee.

\section{Results}

The preliminary Australian lung age equations derived from the Port Lincoln predictive normal equations for spirometry are given in Table 1. The age distribution of Morris' original sample ${ }^{11}$ was strongly skewed to the right, while the Port Lincoln SA sample was evenly age-stratified. ${ }^{24}$ The age distributions of both samples are shown in Figure 1.

\section{Table 1. Preliminary Australian lung age equations.}

\section{Male}

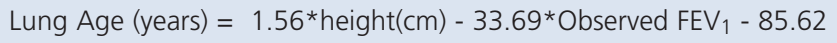

\section{Female}

Lung Age (years) $=1.33 *$ height $(\mathrm{cm})-31.98 *$ Observed FEV $1-74.65$

Derived from contemporary Australian predictive equations for adults of Caucasian origin, aged between 25 and 74 years. 
Figure 1. Age distributions for the Morris sample (1971) and the Australian sample (2008). A: The Morris sample is strongly skewed to the right. B: The Australian sample is evenly age-stratified.

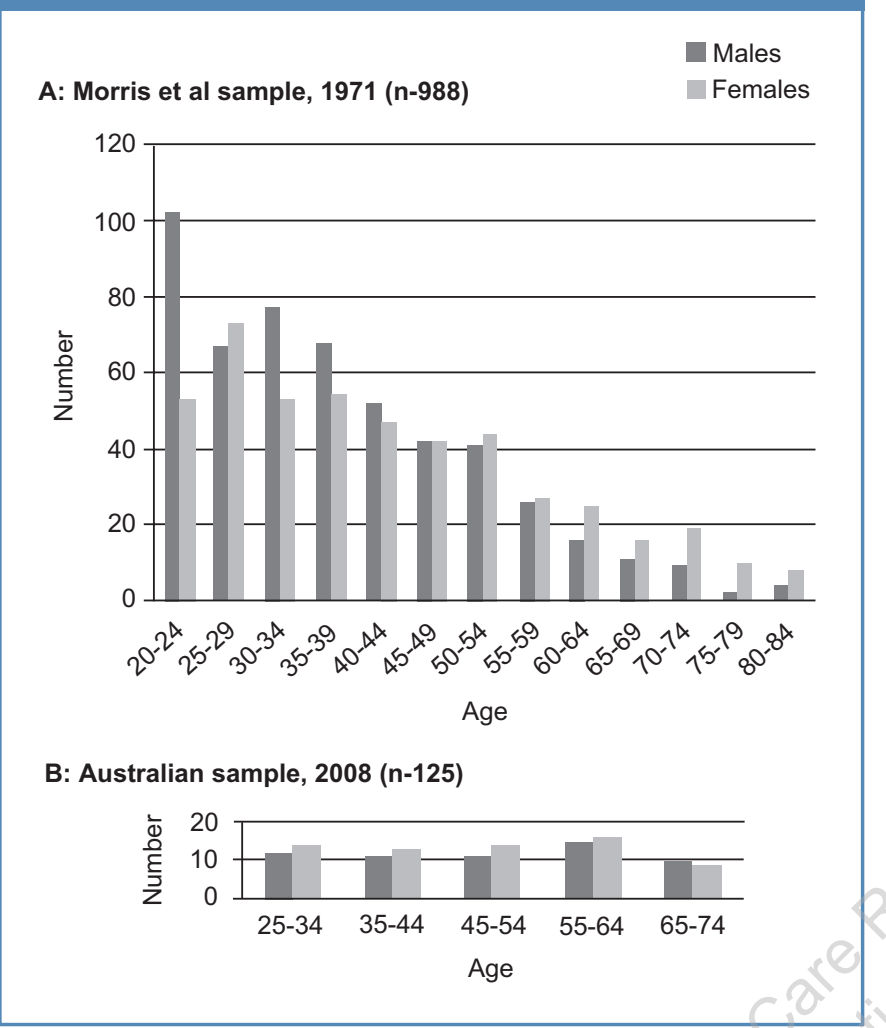

Demographic and clinical characteristics of the CS and the NS groups of the MFS sample are presented in Table 2 .

The ages (mean and range) and the results of thet-tests for the NS and CS sub-groups are presented in Table 3. Diagrammatic representation of results is presented in Figure 2.

\section{Never-smokers}

The mean of the chronological age of the NS group was 42.4 years. The difference of +1.6 years between this and the mean of the lung age estimates (44 years) calculated using the Australian equation was not statistically significant $(p=0.08)$.

\begin{tabular}{|c|c|c|}
\hline & $\begin{array}{c}\text { Current } \\
\text { smokers }\end{array}$ & $\begin{array}{c}\text { Never- } \\
\text { smokers }\end{array}$ \\
\hline$n$ & 50 & 340 \\
\hline Age (range) & $42.9(28-60)$ & $43.1(20-61)$ \\
\hline Height* & $180.2(6.3)$ & $180.3(6.4)$ \\
\hline Weight $^{\dagger}$ & $90.8(11.1)$ & $88.8(11.6)$ \\
\hline $\mathrm{FEV}_{1}^{\ddagger}$ & $4.3(0.7)$ & $4.4(0.7)$ \\
\hline $\mathrm{FVC}^{\ddagger}$ & $5.8(0.8)$ & $5.9(0.8)$ \\
\hline $\mathrm{FEV}_{1} / \mathrm{FVC}^{\S}$ & $73.3(7.3)$ & $75.3(5.9)$ \\
\hline Doctor diagnosis of Asthma, $\mathrm{n}(\%)$ & $8(15.7)$ & $40(11.8)$ \\
\hline $\begin{array}{l}\text { Productive cough, } \mathrm{n}(\%) \\
\text { - Mornings for more than } 3 \text { months } \\
\text { - Rest of day or night for more than } \\
3 \text { months }\end{array}$ & $\begin{array}{l}12(23.5) \\
6(11.8)\end{array}$ & $\begin{array}{l}16(4.7) \\
7(2.1)\end{array}$ \\
\hline
\end{tabular}

The difference of -18.1 years in the means of chronological age and the lung age estimates using the Morris equation (24.3 years) was statistically significant $(p<0.001)$.

\section{Current smokers}

The mean of the chronological age in the CS group was 42.9 years. The difference of +7.5 years between this and the mean of the lung age estimates (50.5 years) calculated using the Australian equation was statistically significant $(p=0.007)$. In the comparisons using the Morris lung age equation the difference (-12.4 years) in the means of chronological age and lung age estimates (30.5 years) was also statistically significant $(p<0.001)$.

\section{Discussion}

Preliminary lung age equations for adult Australian male Caucasians have been validated using the NS sub-group (males) of the MFS independent dataset. In this never-

Table 3. Paired t-test results comparing lung age estimates with chronological age, using the MFS dataset.

\begin{tabular}{|c|c|c|c|c|c|}
\hline & & Mean & SD & $\mathrm{t}(\mathrm{DF})$ & $\mathrm{p}$ value \\
\hline \multirow[t]{3}{*}{ Never-smokers } & Chronological age & 42.37 & Range: 20-61 & & \\
\hline & Australian lung age & 43.95 & 18.66 & $-1.8(339)$ & 0.08 \\
\hline & Morris lung age & 24.3 & 17.89 & 21.2(339) & $<0.001 *$ \\
\hline \multirow[t]{3}{*}{ Current smokers } & Chronological age & 42.88 & Range: $28-60$ & & \\
\hline & Australian lung age & 50.54 & 22.52 & $-2.8(49)$ & $0.007^{*}$ \\
\hline & Morris lung age & 30.52 & 20.87 & 4.9(49) & $<0.001$ * \\
\hline
\end{tabular}

Mean (Range) of chronological age of each sub-group; Mean and SD of lung age estimates using the Australian lung age equation and the Morris lung age equation. $\mathrm{SD}=$ Standard Deviation; $\mathrm{t}=\mathrm{t}$ value; $\mathrm{DF}=$ degrees of freedom; * $=$ statistically significant $<0.05$. 


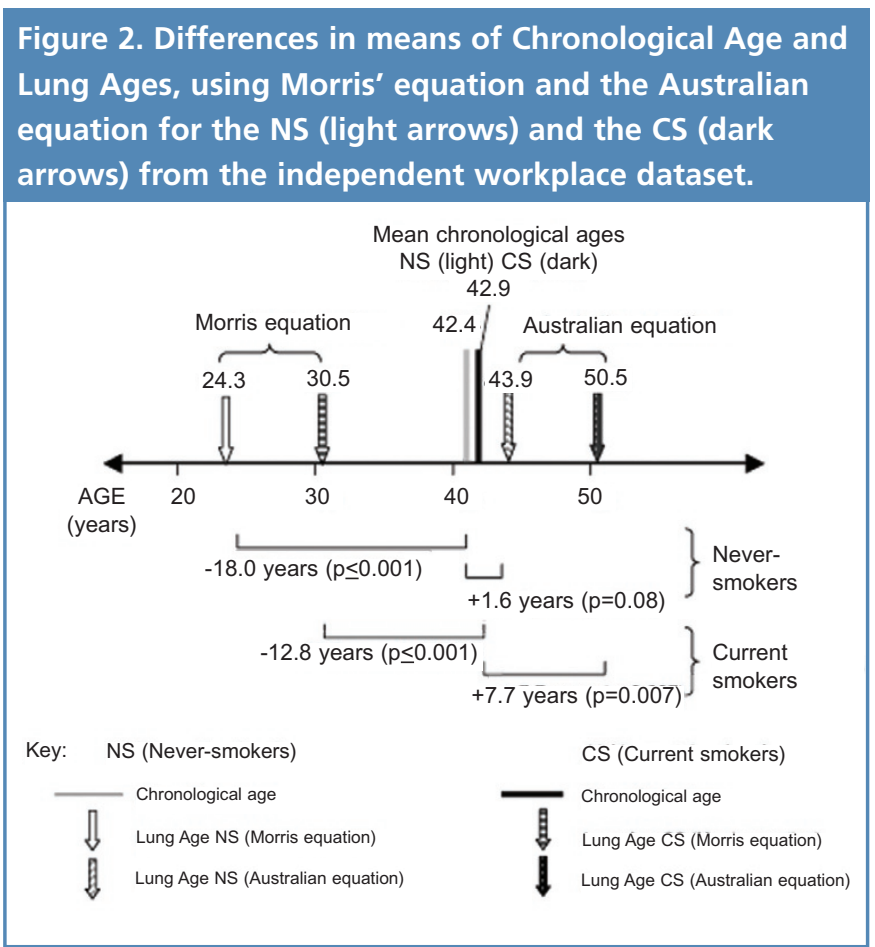

smoking sub-group, the contemporary Australian mean lung age closely agrees with the mean chronological age. However, the Morris equation calculates a lung age that is lower than the chronological age by approximately 18 years when applied to this never-smoking sub-group. This is a strong indication that the Morris lung age equations are not relevant for a current day Australian population.

In the CS sub-group the Australian lung age equation produced a lung age greater than chronological age suggesting that smoking causes lungs to deteriorate more quickly than the expected age-related decline, as predicted by Fletcher and Peto. ${ }^{3}$ In contrast, the Morris equation again produced lung age values Tess than chronological age (approximately 12 years lower) when applied to the CS subgroup. This result seems paradoxical in suggesting that smokers' lungs are 'younger' and presumably healthier than expected. There was indeed a difference of approximately 20 years in the lung age estimates produced by the Morris equations and the new equations in this current smoker subgroup.

These results mean that we can reject the null hypothesis that we would see no difference in the means of the lung age estimates produced by both lung age equations.

There are several possible reasons for this significant result and it is possible that all play a role. Firstly, the predictive equations that are the basis of the Morris lung age equations are approximately 40 years old. The cohort effect suggests that a 40 year-old today will not be the same as someone of the same age 40 years ago due to demographic and environmental differences. ${ }^{22}$ Respiratory testing equipment and procedures have been progressively refined over the last 40 years in line with recommendations that have been regularly updated by the ATS. ${ }^{22,25-28}$ In particular, the Morris, Koski and Johnson results" ${ }^{11}$ were calculated using equipment and methods that may well give lower results than those currently recommended by the ATS. ${ }^{29}$ Indeed this study predates even the first ATS guidelines on spirometry. ${ }^{25}$

Secondly, $79 \%$ of Morris' original sample was from two church groups in rural USA. ${ }^{11}$ As the doctrines of these two churches forbid tobacco smoking and the intake of alcohol or caffeine as well as advocating a vegetarian diet, this sample can't be described as representative of a 'normal' current day population. The SA sample was drawn from the broad rural community, targeting non-smokers with no history of lung disease. ${ }^{24}$

A third reason could be that the age distribution of the Morris sample was strongly skewed to the right with over 30\% of subjects in the youngest 10 year age bracket (Figure 1A)." This may mean that results are biased towards younger ages. One of the strengths of our SA sample was that it was evenly age-stratified, resulting in predictive equations that are equally relevant across the whole age range (Figure 1B).

A limitation of this study is that lung age is an estimated value based on the population mean and as such may have potential difficulties when predicting values for individuals. This is demonstrated by the large standard deviations of both lung age equations in Table 3 . The variability of spirometry results of normal healthy subjects is itself quite wide, being approximately $80-120 \%$ predicted, and consequently wide variation in lung age estimates exists. There continues to be considerable debate about use of Lower Limits of Normal (LLN) or percent predicted, with the definitions of stages of disease easily described by percent predicted. Instead of a single lung age value it may be possible to communicate lung age as being "between $x$ and $y$ ", based on 95\% confidence intervals. Lung age's relationship to smoking may also be controversial as there is also a decline in lung function with increasing age as well as with diseases such as COPD. However, there is continued support in the literature for the more rapid decline in $\mathrm{FEV}_{1}$ in smokers than in non-smokers. ${ }^{3,30-32}$ Other factors that also influence lung function throughout life include gestational age at birth, genetics, childhood infections, and environmental factors such as air quality and workplace exposures.

A further limitation of this study is that we have used predictive equations developed from a pilot study of 125 adults to produce the preliminary Australian lung age equations. However, this contemporary sample was comprised of healthy non-smokers and was evenly age- and sex-stratified. The predicted values for each of the spirometric parameters derived in the Port Lincoln study are remarkably similar to those 


\section{Summary box}

What is already known:

- The Morris lung age equations in current use were produced in 1985, but are based on data published in 1971.

- Lung age has been shown to be an acceptable way to communicate spirometry results for smokers and patients with COPD.

- Lung age has had a positive impact on the quit rate in an RCT.

What this study adds:

- This study shows that Morris' equations significantly underestimate lung age in both Australian never-smokers and smokers.

- New lung age equations produce lung age estimates that are approximately 20 years greater than does the Morris equation, for Australian never-smoking and current smoking males.

Implications:

- Using the new equations may have a greater impact on smokers, and may increase quit rates further.

- These results highlight the importance of having current predictive equations available.

reported by Gore et al. in a previous study on a larger random sample ( $n=1302)$ of the South Australian population. ${ }^{24,33}$ Also, the subjects in the workplace dataset may not be representative of a normal population; they maintain a high level of fitness but contrarily have occasional occupational exposures to smoke when attending fires. The accuracy of the estimates of lung age for the NS subgroup using the Australian equation suggests that they are representative of the population.

\section{Summary}

Lung age can be calculated by modern spirometers and is a concept that can be easily communicated. In primary care, where much of the smoking cessation counselling takes place, lung age can be used as a simple non-pharmacological intervention to motivate smokers to quit. We have used contemporary data to produce preliminary lung age equations for adult Australians of Caucasian ethnicity (aged 25-74 years). International guidelines suggest that lung function equations should be derived from the same population to which they will be applied. ${ }^{23}$ Our results strongly suggest that existing lung age equations are in need of review. Contemporary lung age equations can give a more powerful quit smoking message. Further research is planned to validate these equations in females as well as males, using a larger random population sample.

\section{Conflict of interest declaration}

There are no conflicts of interest for any of the authors.

\section{Acknowledgements}

This work has been supported by the PHCRED (Primary Health Care Evaluation and Development) Program at the Discipline of General Practice at the University of Adelaide in the form of a seeding grant in 2007 and a Researcher Development Program (RDP) Fellowship in 2008. The PHCRED Program is funded by the Australian Government Department of Health and Ageing.

\section{Authors' roles}

Wendy Newbury: literature search, data collection, analysis, writing of article Jonathan Newbury: analysis, writing of article Nancy Briggs: statistical analysis, writing of article Alan Crockett: analysis, writing of article

\section{References}

1 Doll $R$, Hill $A B$. The mortality of doctors in relation to their smoking habits: a preliminary report: (Reprinted from Br Med J 1954:ii;1451-5). BMJ 2004;328(7455):1529-33. http://dx.doi.org/10.1136/bmj.328.7455.1529

2 Doll R, Peto R, Boreham J, Sutherland I. Mortality in relation to smoking: 50 years' observations on male British doctors. BMJ 2004;328:1519-28. http://dx.doi.org/10.1136/bmj.38142.554479.AE

3 Fletcher C, Peto R. The natural history of chronic airflow obstruction. BMJ 1977; 1:1645-48.

4 James $A$, Palmer $L$, Kicic $E$, et al. Decline in lung function in the Busselton Health Study. The effects of asthma and cigarette smoking. Am J Respir Crit Care Med 2005;171:109-14. http://dx.doi.org/10.1164/rccm.200402-2300C

5 Kohansal R, Martinez-Camblor P, Agusti A, et al. The natural history of chronic airflow obstruction revisited. An analysis of the Framingham Offspring Cohort. Am J Respir Crit Care Med 2009;180:3-10. http://dx.doi.org/ 10.1164/rccm.200901-00470C

6 Peat J, Woolcock A, Cullen K. Decline of lung function and development of chronic airflow limitation: a longitudinal study of non-smokers and smokers in Busselton, Western Australia. Thorax 1990;45:32-7. http://dx.doi.org/ 10.1136/thx.45.1.32

7 Wright J, Hobson J, Wiggs B, Pare P, Hogg J. Effect of cigarette smoking on structure of the small airways. Lung 1987;165:91-100.

8 Kerstjens H, Rijcken B, Schouten J, Postma D. Decline of FEV1 by age and smoking status: facts, figures, and fallacies. Thorax 1997;52:820-27. http://dx.doi.org/10.1136/thx.52.9.820

9 Petty T. Simple office spirometry. Clin Chest Med 2001;22(4):845-59. http://dx.doi.org/10.1016/S0272-5231\%2805\%2970070-8

10 Morris J, Temple W. Spirometric "lung age" estimation for motivating smoking cessation. Prev Med 1985;14(5):655-62.

11 Morris J, Koski A, Johnson L. Spirometric standards for healthy nonsmoking adults. Am Rev Resp Dis 1971;103:57-67.

12 Parker D, Goldman R, Eaton C. A qualitative study of individuals at risk for or who have chronic obstructive pulmonary disease: What do they understand about their disease? Lung 2008;186(5):313-16. http://dx.doi.org/ 10.1007/s00408-008-9091-9

13 Parkes G, Greenhalgh T, Griffin M, Dent R. Effect on smoking quit rate of telling patients their lung age: the Step2quit randomised controlled trial. BMJ 2008;336(7644):598-600. http://dx.doi.org/10.1136/bmj.39503.582396.25

14 Bize R, Burnand B, Mueller Y, Rege W, Cornuz J. Biomedical risk assessment as an aid for smoking cessation (Review). Cochrane Database of Systematic Reviews 2009(2). http://dx.doi.org/10.1002/14651858.CD004705.pub3

15 Lipkus I, Prokhorov A. The effects of providing lung age and respiratory symptoms feedback on community college smokers' perceived smoking-related health risks, worries and desire to quit. Addict Behav 2007;32(3):516-32. http://dx.doi.org/10.1016/j.addbeh.2006.05.018 
16 McLure J, Ludman E, Grothaus L, Pabiniak C, Richards J. Impact of a brief motivational smoking cessation intervention. The Get PHIT Randomized Controlled Trial. Am J Prev Med 2009;37(2):116-23. http://dx.doi.org/ 10.1016/j.amepre.2009.03.018

17 McLure J, Ludman E, Grothaus L, et al. Immediate and short-term impact of a brief motivationsl smoking intervention using a biomedical risk assessment: The Get PHIT trial. Nicotine Tob Res 2009;11(4):394-403. http://dx.doi.org/ 10.1093/ntr/ntp004

18 Mitsumune T, Senoh E, Nishikawa H, Dachi M, Kajii E. The effect of obesity and smoking status on lung age in Japanese men. Respirology 2009;14(5):757-60. http://dx.doi.org/10.1111/j.1440-1843.2009.01541.x

19 Toda R, Hoshino T, Kawayama T, et al. Validation of "Lung Age" measured by spirometry and handy electronic FEV1/FEV6 meter in pulmonary diseases. Intern Med 2009;48(7):513-21. http://dx.doi.org/10.2169/internalmedicine.48.1781

20 Van Schayck OCP, Pinnock H, Ostrem A, et al. IPCRG Consensus statement: Tackling the smoking epidemic - practical guidance for primary care. Prim Care Resp J 2008;17(3):185-93. http://dx.doi.org/10.3132/prcj.2008.00060

21 The Tobacco Use and Dependence Clinical Practice Guideline Panel, Staff, and Consortium Representatives. A Clinical Practice Guideline for Treating Tobacco Use and Dependence: A US Public Health Service Report Journal of the American Medical Association 2000;283(24):3244-54. http://dx.doi.org/ 10.1001/ jama.283.24.3244

22 American Thoracic Society. Lung Function Testing: Selection of reference values and interpretative strategies. Am Rev Resp Dis 1991;144:1202-18.

23 Pellegrino R, Viegi G, Brusasco V, et al. Interpretive strategies for lung function tests. Eur Resp J 2005;26:948-68. http://dx.doi.org/10.1183/ 09031936.05 .00035205
24 Newbury W, Crockett A, Newbury J. A pilot study to evaluate Australian predictive equations for the Impulse Oscillometry System. Respirology 2008;13(7):1070-75. http://dx.doi.org/10.1111/j.1440-1843.2008.01375.x

25 American Thoracic Society. ATS Statement - Snowbird workshop on standardization of spirometry. Am Rev Resp Dis 1979;119(5):831-8.

26 American Thoracic Society. Standardization of spirometry - 1987 update. Am Rev Resp Dis 1987;136(5):1285-98.

27 American Thoracic Society. Standardization of spirometry - 1994 update. Am J Respir Crit Care Med 1995;152(3):1107-36.

28 Miller M, Hankinson J, Brusasco V, et al. Standardisation of spirometry. Eur Resp J 2005;26(2):319-38. http://dx.doi.org/10.1183/09031936.05.00034805

29 Miller A, Thornton J. The interpretation of spirometric measurements in epidemiologic surveys. Environ Res 1980;23(2):444-68. http://dx.doi.org/10.1016/0013-9351(80)90078-X

30 Bernhard D, Moser C, Backovic A, Wick G. Cigarette smoke - an aging accelerator? Exp Gerontol 2007;42:160-5. http://dx.doi.org/10.1016/ j.exger.2006.09.016

31 Knuiman $M$, James $A$, Divitini $M$, et al. Lung function, respiratory symptoms, and mortality: results from the Busselton Health Study. Ann Epidemiol 1999;9:297-306. http://dx.doi.org/10.1016/\$1047-2797(98)00066-0

32 MacNee W. Accelerated lung aging: a novel pathogenic mechanism of chronic obstructive pulmonary disease (COPD). Biochem Soc Trans 2009;37:819-23. http://dx.doi.org/10.1042/BST0370819

33 Gore C, Crockett A, Pederson D, et al. Spirometric standards for healthy adult lifetime nonsmokers in Australia. Eur Resp J 1995;8(5):773-82. http://dx.doi.org/10.1183/09031936.95.08050773 